deals with the properties of solutions of high polymers in general. It overlaps, but is complementary to, a somewhat similar chapter in volume 2 . The main topics are, of course, the solubility, vapour pressure and osmotic pressures of their solutions, since the separation of heterodisperse polymers and the estimation of molecular weight can only be confidently carried out provided there is in existence a sufficient amount of knowledge concerning these solutions. The viscosity of dilute solutions is also a relevant topic here. A critical and extended discussion on this phase of the work would have been welcome. The Staudinger equation has come in for a good deal of criticism, often uninformed, and it would have been extremely useful for the many who are forced to employ this method for measuring molecular weights, out of convenience, to have had a critical summary of this very controversial subject.

In short, therefore, this volume is a mine of invaluable information and suggestive commentary on high polymer systems, especially in those regions of contact with the biological side. For the biologist it is appropriately complete in itself; for those interested primarily in high polymers the other volumes in the series will satisfy all reasonable needs where volume 4 is somewhat abridged. The work of translation has been excellently done by Dr. L. E. R. Picken. The author, translator and publishers alike must be accorded a word of gratitude for having produced, under most difficult international conditions such a valuable addition to this series of volumes.

H. W. Melville.

\section{VENEREAL DISEASE IN GREAT BRITAIN}

Venereal Disease in Britain

By Sydney M. Laird. Pp. 80. (Harmondsworth and New York: Penguin Books, Ltd., 1943.) 9d. net.

D . SYDNEY LAIRD'S views on the subject of control and compulsion as a means of reducing the incidence of venereal diseases have already been presented by him to his colleagues in venereology. His expressions can be taken as a fair cross-section of specialist medical opinion. This book is a statement of facts and an appeal to the reader to apply the knowledge he can obtain in his reading to the taskhis public duty-of helping to reduce the amount of venereal diseases. Elimination of the stigma attached to the diseases must accompany the newspaper and radio drive to increase the public knowledge of the subject. A short outline of the historical background precedes a simple explanation of the common signs, symptoms, and complications of gonorrhœe and syphilis. A typical case history illustrates the train of events which follow when an ignorant man is exposed to infection. The reviewer can vouch that the example chosen is no unlikely theoretical case.

The treatment of venereal diseases by well-meaning but uninstructed general practitioners--increasing since the advent of $\mathrm{M}$ and $\mathrm{B} 693$-is justly decried.

Venereal diseases are not notifiable in Great Britain. Free diagnostic and treatment facilities are provided, but the sufferer must voluntarily present himself, and if he defaults from treatment while still infectious there is no way of compelling him to return. This voluntary system has had a very long time in which to prove itself, and the 70 per cent increase in the incidence of early syphilis since 1939 has proved its complete inadequacy to deal with the present situation. Regulation 33B aims only at a very small section of the community and is unlikely to make a noticeable impression.

The successful Swedish venereal disease control system is described. Treatment is compulsory, but facilities are free both for out-patients and for inpatients. Notification does not disclose the patient's name. The source of infection and any contacts of the infectious person can be compelled to attend for examination and for treatment if necessary. Legal powers are available to deal with anyone who defaults from treatment while still in an infectious state. In practice 97.5 per cent of cases attend until they are certified free of venereal disease in a communicable form, and legal intervention is very rarely needed. Compare this with an instance in an English clinica fair specimen-where 50 per cent of syphilis and 30 per cent of gonorrho:a cases defaulted before treatment was complete.

Dr. Laird asks for education of the public and for compulsory powers run on the Swedish - pattern, which will, of course, rarely be used in an enlightened community. The medical facilities are already available and adequate.

Finally, there are some illustrative statistical tables, British and Swedish, and a résumé of the relevant clauses of the Swedish anti-venereal laws.

The first half of this book should interest and inform any lay reader, and it is to be hoped that the second half will have the author's desired effect of stimulating the intelligent reader into individual effort in helping to stamp out venereal disease.

\section{PROTECTION OF ELECTRIC POWER SYSTEMS}

Automatic Protection of A.C. Circuits

By G. W. Stubbings. Third edition, revised. Pp. viii + 320. (London : Chapman and Hall, Ltd., 1943.) 18s, net.

THERE are not so many text-books on circuit and machine protection that the present edition of the author's well-known work is not welcome, especially as it has been brought right up to date. The potential power in modern rotating machinery and transmission circuits is so great that one need not wonder at the simplicity and robustness of the design, maintenance, and testing of the apparatus which is relied on to prevent a major disaster on a fault developing and spreading. At the same time that faulty elements in a system are de-energized by the protection system, it is evident that power must be maintained in as much of the rest of the system as possible. The author therefore outlines the development of protection, the design and interconnexion of the necessary voltage and current transformers, and gives a full description of the relays necessary for the sequential or distance control of the circuits to be protected. A chapter on symmetrical components is given so that protection schemes depending on this conception may be the better appreciated. The author concludes his useful survey with an account of the protection of plant, testing, references to relevant literature, and a glossary of the technical terms used in the art. The stability of power supply in Great Britain and the rarity of major breakdowns is the result of the careful application of this protection technique.
L. E. C. Hughes. 